\title{
Medicolegal neglect? The case for physical activity promotion and Exercise Medicine
}

\author{
Richard Weiler, ${ }^{1}$ Peter Feldschreiber, ${ }^{2}$ \\ Emmanuel Stamatakis ${ }^{3}$
}

\section{INTRODUCTION}

Whether measured subjectively or objectively, a large proportion of the population are living sedentary and physically inactive lives. ${ }^{1} 2$ This should be a major public health focus given the overwhelming evidence demonstrating that physical inactivity increases an individual's risk for all-cause mortality and may be one of the leading causes of non-communicable chronic disease in the world, responsible for about $60 \%$ of worldwide deaths $s^{3-6}$ and probably more in developed countries.

Pandemic levels of physical inactivity result in a huge burden of unhealthy consequences within populations and for society, across all socioeconomic classes, all ethnicities and phenotypes.

However, attempts to explain the precise causes of chronic diseases and resultant deaths, for each individual, are very difficult. We are all exposed to multiple risk factors in variable quantities throughout our lives and, currently, these are virtually impossible to measure. Consequently, despite our remarkable growth in the medical field, explanations for precise causes of death remain speculative. To attribute causal status of risk factors for non-communicable disease is fraught with difficulty both clinically and medicolegally. For example, it is baffling that despite scientific progress since Richard Doll's landmark findings 60 years ago, strongly linking smoking with lung cancer, ${ }^{7}$ causation of smoking and lung cancer has still not been upheld in a court of law. ${ }^{8}$

\footnotetext{
${ }^{1}$ Homerton University Hospital NHS Foundation Trust, London, UK

2Barrister, Medical and Healthcare Law, 4 New Square Chambers, London, UK

${ }^{3}$ Department of Epidemiology and Public Health, University College London, London, UK
}

Correspondence to Richard Weiler, Specialist Registrar in Sport \& Exercise Medicine, Homerton University Hospital NHS Foundation Trust, Homerton Row, LondonE96SR, UK; rweiler@doctors.org.uk

\section{DUTY OF CARE}

Duty of care is a legal obligation imposed on a doctor requiring, via the Bolam test, ${ }^{9}$ that their actions conform to those of a responsible body of professional opinion, even if others have a different opinion. More recently, the Bolitho $\mathrm{v}$ City and Hackney Health Authority case, entitled a judge to choose between two bodies of expert opinion and reject an opinion, which is 'logically indefensible'. ${ }^{10}$

In the UK, duty of care, in the form of National Institute for Health and Clinical Excellence and Royal College guidelines, currently represents an evidencebased responsible body of professional opinion relating to clinical care. Medical ethics, including patient autonomy, nonmaleficence, beneficence and informed consent, guide our medical care, when guidelines are not always appropriately applied. Medical defence unions providing medical indemnity repeatedly recommend that our professional and clinical decisions be documented in medical records and note keeping, including those situations when guidelines are not suitable.

Numerous responsible bodies of professional opinion have recognised the extensive evidence base, cost-effectiveness and importance of physical activity promotion as a primary prevention and secondary treatment for various diseases. Physical activity promotion features in 39 national guidelines (table 1), even excluding physical activity-specific guidelines. On this basis, if a doctor managing a patient with any of these diseases has not followed these guidelines and advised or signposted appropriately on physical activity, then it is possible that medical negligence has ensued. Furthermore, would it be 'logically indefensible' for doctors not to promote physical activity for these patients, regardless of their personal opinions and learning needs?

Given the technology and functionality of primary care computerised medical records, it would be relatively cheap and simple to embed such recommendations within standard note keeping templates to help guide practitioners through the forgotten and fundamental basis of these guidelines, ensure medicolegal defensibility, should the need arise, and reduce the potential risk of medical-negligence proceedings.

Critics will argue that physical activity promotion is a lifestyle choice, however, so are smoking and alcohol consumption and yet these are medically accepted risk factors worthy of our clinical behaviour change efforts and consultation time. In many countries around the world, exercise and tailored physical activity are used by trained Sport and Exercise Medicine (SEM) specialists working within multidisciplinary teams, to both treat and prevent various chronic diseases. Unfortunately, in the UK, there are many patients with chronic diseases, risk factors and comorbidities, who are essentially excluded from physical activity. Their attending doctors invariably lack the knowledge to provide them with necessary physical activity and behaviour change advice (or exercise prescription), are fearful of perceived physical activity risks and resulting litigation, or cannot access specialist National Health Service (NHS) SEM services, despite the existence of an emerging trained specialist SEM workforce seeking NHS employment. Ironically, these patients stand to gain the most from intervention (as does the NHS), yet remain unlikely to receive this advice, being advised to rest, risking further health and well-being detriment.

The responsibility for delivering Exercise Medicine in the UK is left in the hands of doctors who do not understand the basic science behind physical activity, benefits, risks, doses or methods to change complex physical inactivity behaviours. Why can we rightly refer to a dietitian for assistance with disordered eating habits and still not refer to an SEM specialist on the NHS for specialist Exercise Medicine care, when appropriate?

\section{AN INSTITUTIONAL AND EDUCATIONAL PROBLEM}

General Medical Council (GMC) guidance on 'Good Medical Practice' suggests that doctors should 'protect and promote the health of patients and the public'. ${ }^{11}$ Yet physical activity promotion remains un-rewarded in primary care, ${ }^{6}$ Exercise Medicine is not on the core curriculum of many medical schools ${ }^{12}$ and most doctors are not trained to deliver physical activity promotion and behaviour change. 


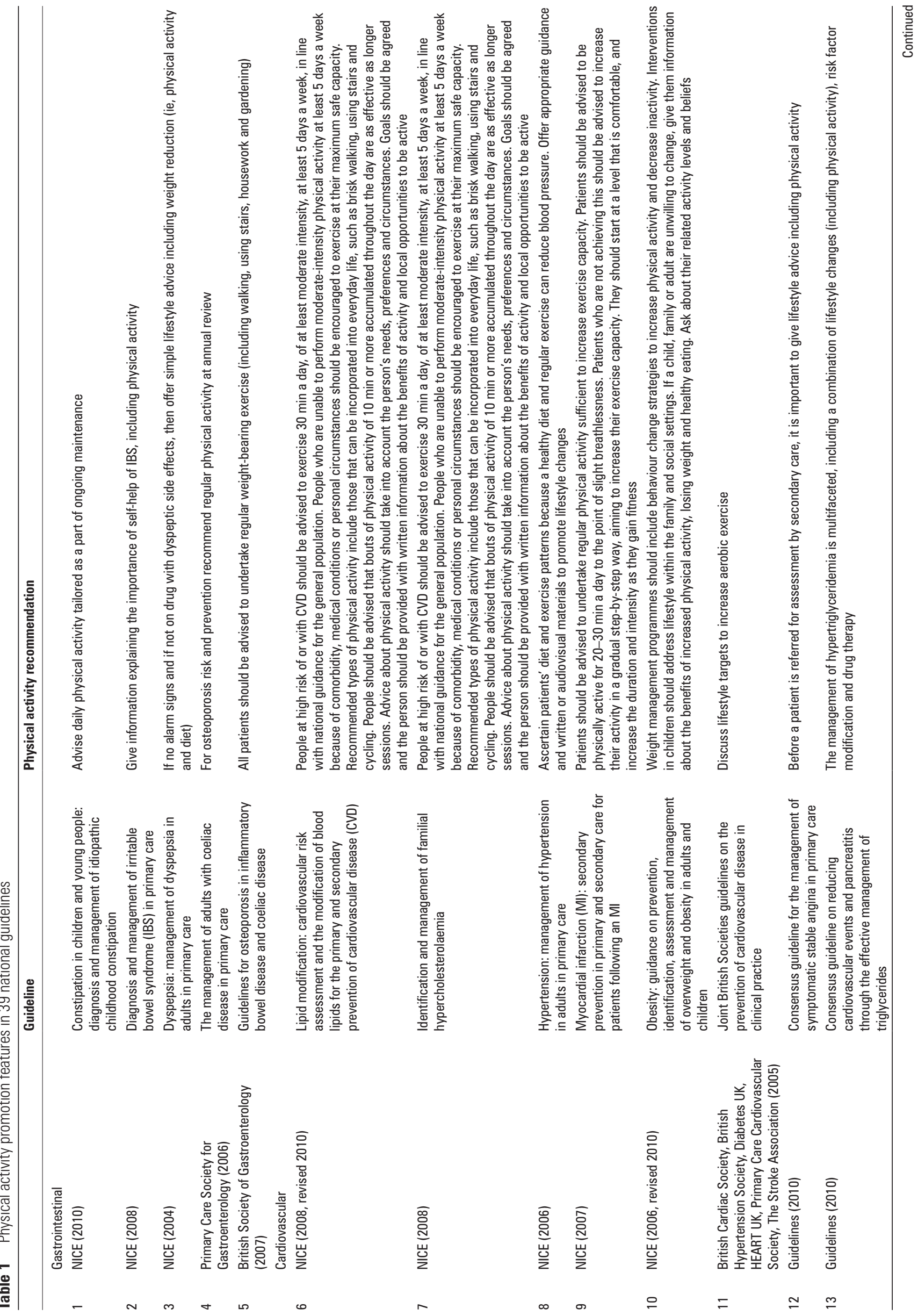

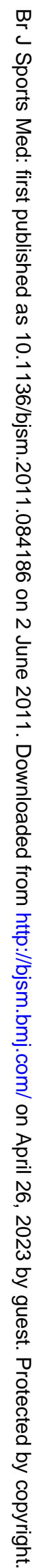




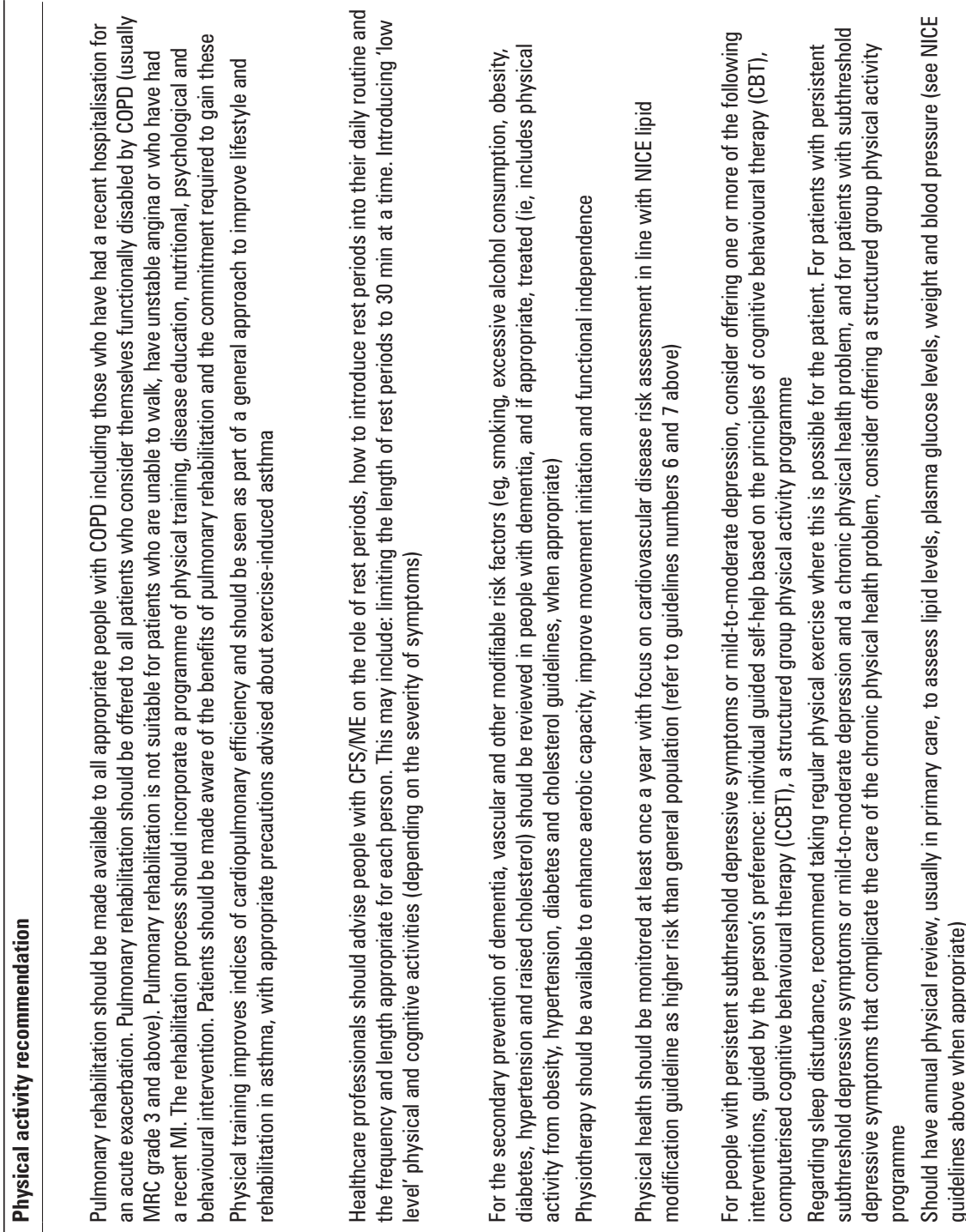

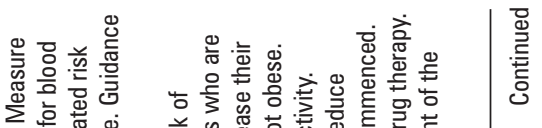

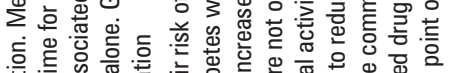

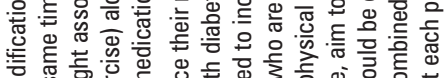

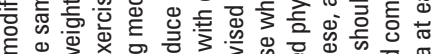

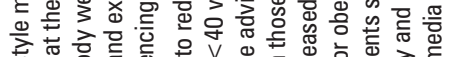

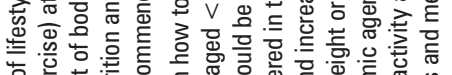

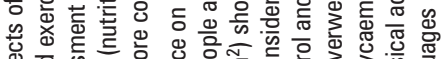

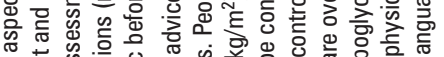

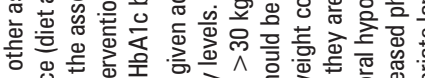

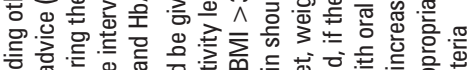

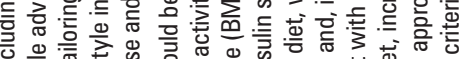

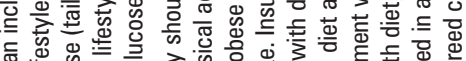

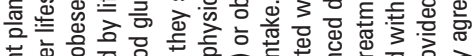

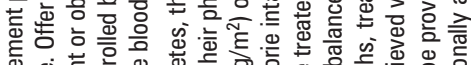

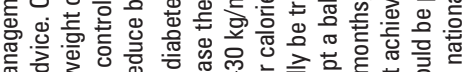

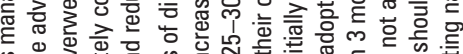

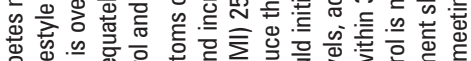

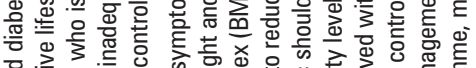

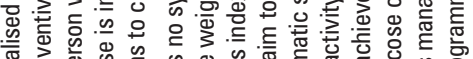

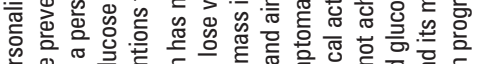

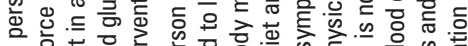

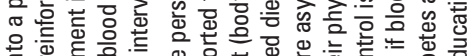

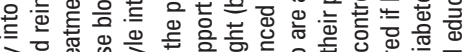

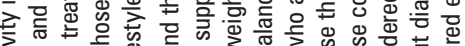

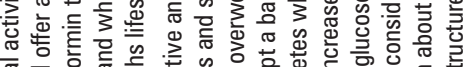

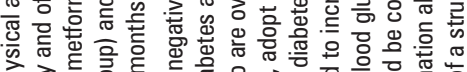

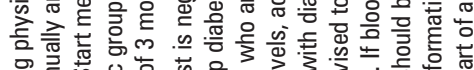

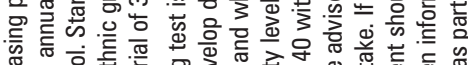

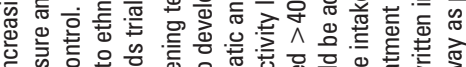

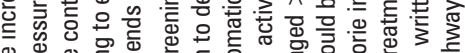

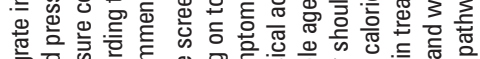

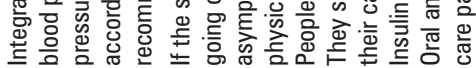

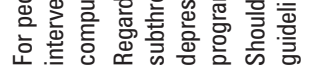

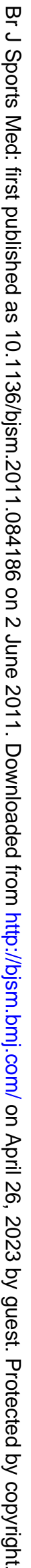

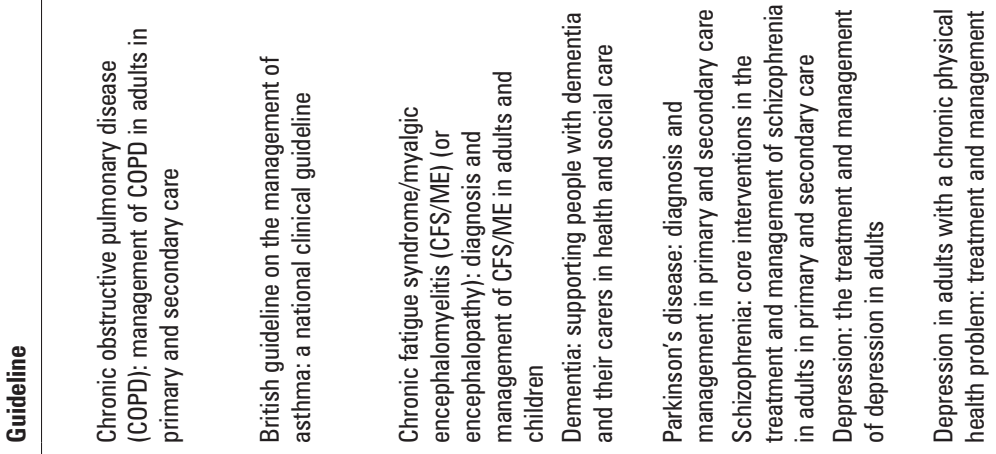
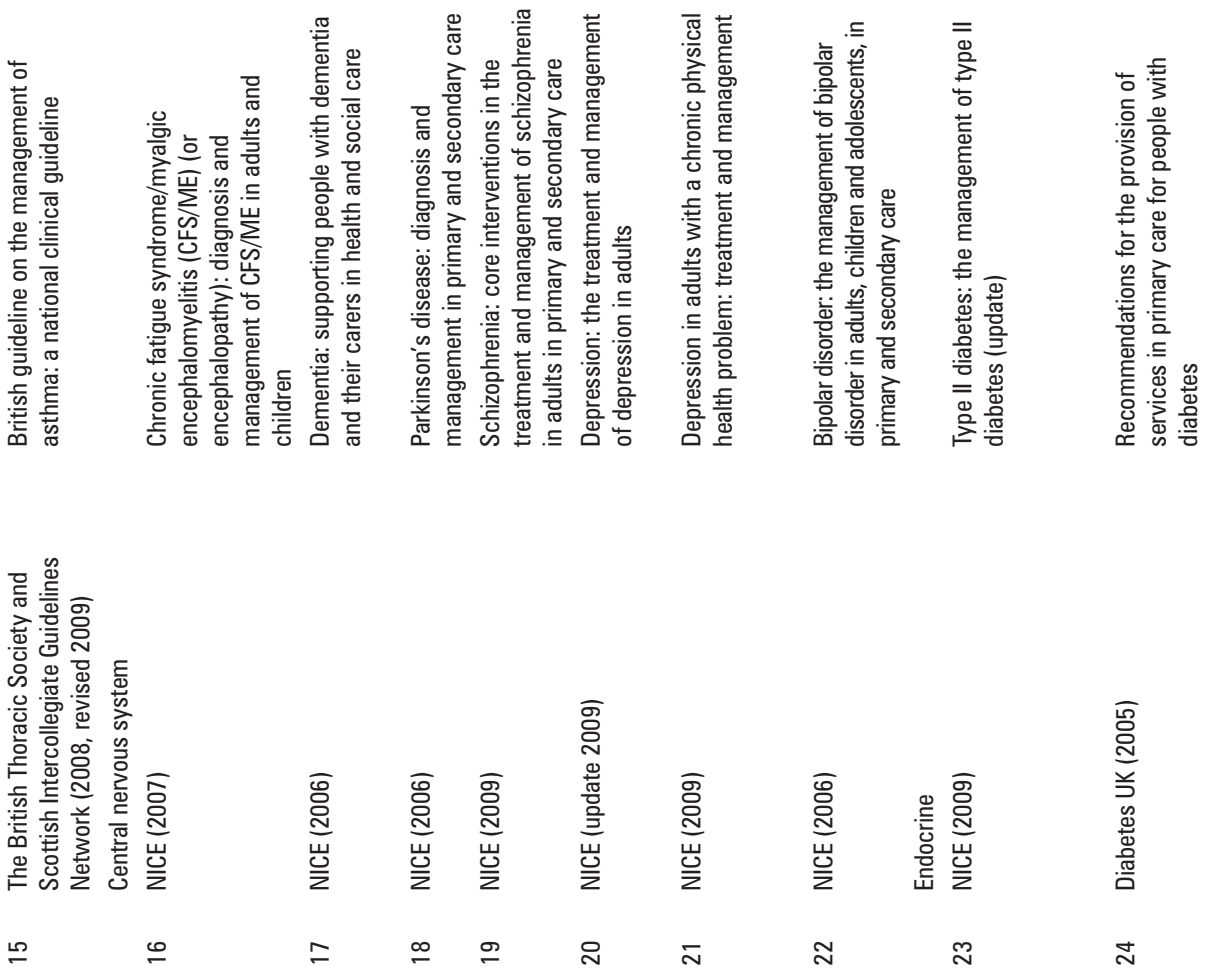


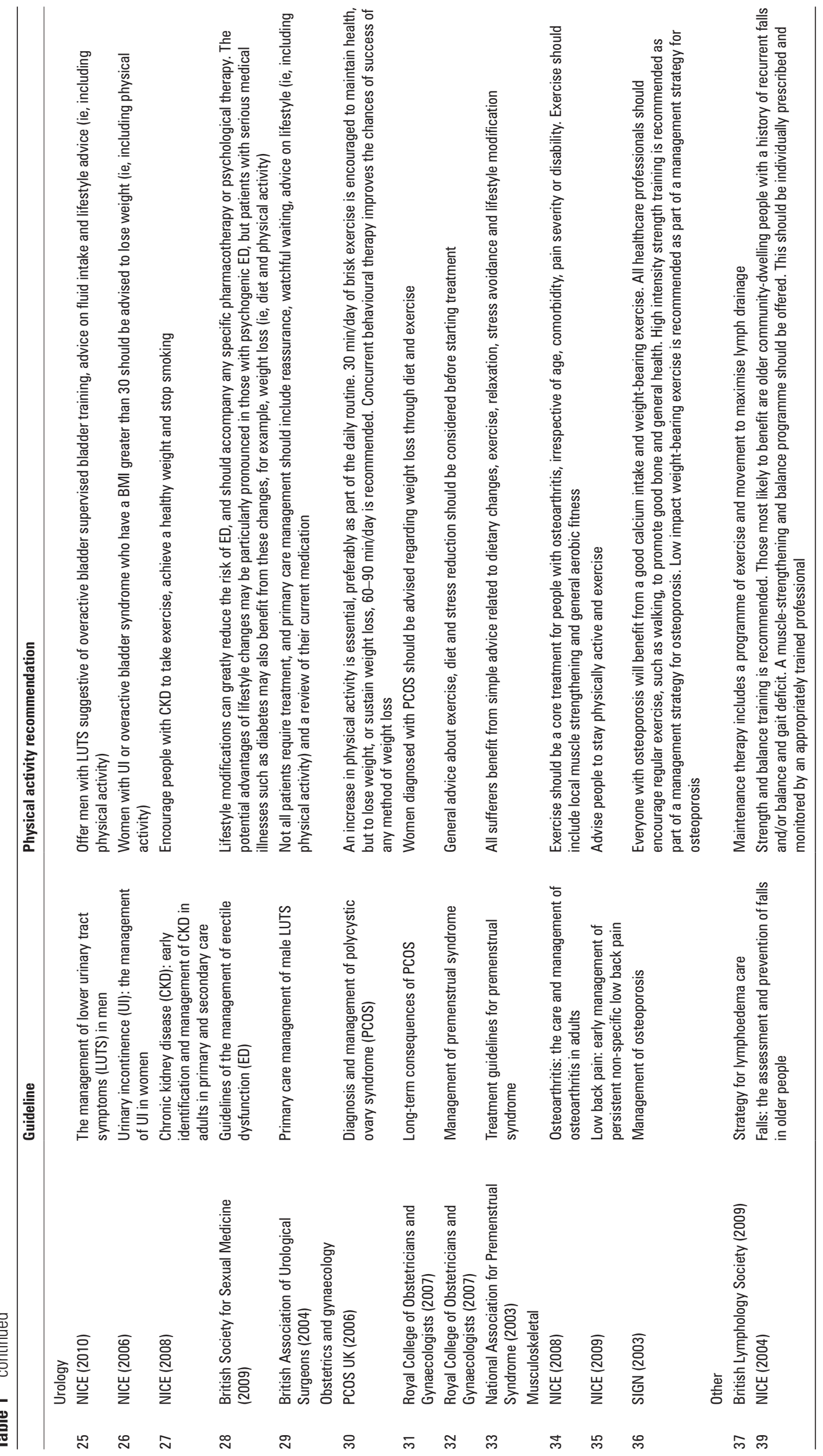


Regulatory authorities, such as the GMC, are now responsible for standards of medical education, in a position to focus future medical practice and ensure that preventive medicine and wellness promotion feature as highly as treatment of illness in the future. The GMC regulates undergraduate medical education and, regrettably, physical activity does not feature as a curricula requirement (Tomorrow's Doctors 2003 and 2009). In addition, it is not specifically covered in GMC medical school quality assurance reviews. The GMC, like doctors, may have a responsibility and duty of care to the public and their future members to review medical school curricula requirements relating to the promotion of health and prevention of disease with greater emphasis and guidance for physical activity education. Only then, will future doctors be optimally educated to deliver behaviour and lifestyle change for the prevention and treatment of illness, which are embedded within ever-increasing guidelines.

\section{UK PUBLIC HEALTH STRATEGY}

In the UK NHS, the introduction of the Responsibility Deal and GP commissioning, will probably place more health strategy decisions in the hands of corporate stakeholders and 'willing providers'. Hidden agendas, such as profitability, may influence important public health rationing decisions and perceived unprofitable physical activity promotion and Exercise Medicine may well continue to suffer. Unfortunately, very few private stakeholders stand to benefit from better population health, which, worryingly, means that corporate agendas could direct national health strategies and leave Exercise Medicine largely aspirational and marginalised. In brief, for the current evidence base to be translated into commissioned NHS Exercise Medicine services in the UK, there is an urgent need for strong evidence to demonstrate cost-effectiveness, improved patient care pathways and outcomes for such services.

\section{SUMMARY}

Medical science has shown that low cardiorespiratory fitness (resulting from sedentary behaviour) is one of, if not, the most important risk factors for all-cause mortality, ${ }^{13}$ yet clinical practice, medical education and public health strategy continue to focus on all other risk factors except sedentary behaviour. Physical activity promotion is embedded within a large number of ever-increasing clinical guidelines with strong supporting evidence, both medical and cost-effective, delivering positive clinical messages and medicolegal responsibility to healthcare practitioners.

Is it possible that there may be a time when a lawyer cross examines a doctor in the witness stand, asking why they did not address their sick or dead patients' physical inactivity, citing clinical guidelines, because it is known to be one of the highest modifiable risk factors for morbidity and mortality? Physical activity promotion is one of the first treatment recommendations in numerous clinical guidelines with a good reason and should no longer be medically neglected.

Physical activity failings are institutionally embedded within our environment, medical practice, education and culture. The public are being let down on physical activity promotion, treatment choices (eg, Exercise Medicine), preventive medicine, the sedentary environment, corporate influences, a lack of physically active medical role models and failed by a lack of funding for physical activity and inactivity research. All resulting in between approximately 27-59 million $^{14}$ people in the UK alone, when measured subjectively and objectively, respectively, ${ }^{15}$ literally sitting in a pre-disease or disease state caused by physical inactivity probably the biggest silent killer of our times.

\section{Competing interests None.}

Provenance and peer review Not commissioned; externally peer reviewed.
Accepted 27 April 2011

Published Online First 2 June 2011

Br J Sports Med 2012;46:228-232.

doi:10.1136/bjsm.2011.084186

\section{REFERENCES}

1. Weiler R, Stamatakis E, Blair S. Should health policy focus on physical activity rather than obesity? Yes. BMJ 2010;340:c2603. http://www.bmj.com/ content/340/bmi.c2603.full.

2. Chief Medical Officer. On the State of the Public Health. Annual Report of the Chief Medical Officer, 2009. http://www.dh.gov.uk/prod_consum_dh/ groups/dh digitalassets/@dh/@en-enps/ documents/digitalasset/dh_114012.pdf (accessed 26 May 2011).

3. Department of Health and Human Services. 2008 Physical Activity Guidelines for Americans, 2008. http://www.health.gov/paguidelines/pdf/paguide.pdf (accessed 26 May 2011).

4. Department of Health. At Least Five a Week Evidence on the Impact of Physical Activity and Its Relationship to Health, 2004. http://www.dh.gov. uk/prod_consum_dh/groups/dh_digitalassets/@ dh/@en/documents/digitalasset/dh 4080981.pdf (accessed 26 May 2011).

5. World Health Organization. Global Strategy on Diet, Physical Activity and Health. WHO, 2004.

6. Weiler $\mathbf{R}$, Stamatakis E. Physical activity in the UK: unique crossroad? Br J Sports Med 2010;44:912-14. http://bjsm.bmj.com/content/44/13/912.full.

7. Doll R, Hill AB. Smoking and carcinoma of the lung; preliminary report. Br Med J 1950;2:739-48.

8. McTear v Imperial Tobacco Ltd [2005] Scot CS 69 (31 May 2005).

9. Bolam v Friern Hospital Management Committee [1957] 2 All ER 118-28.

10. Bolitho v City and Hackney Health Authority [1997] 4 All ER 771.

11. General Medical Council. Good Medical Practice. GMC 2006. http://www.gmc-uk.org/static/documents/ content/GMP_0910.pdf (accessed 26 May 2011).

12. Cullen M, McNally O, Neill SO, et al. Sport and exercise medicine in undergraduate medical schools in the United Kingdom and Ireland. Br J Sports Med 2000;34:244-5

13. Blair SN. Physical inactivity: the biggest public health problem of the $21^{\text {st }}$ century. Br J Sports Med 2009;43:1-2.

14. Let's Get Moving. Commissioning Guidance. A New Physical Activity Care Pathway for the NHS. Department of Health, 2009:28 http://www.dh.gov. uk/prod_consum_dh/groups/dh_digitalassets/ documents/digitalasset/dh 1059̄44.pdf.

15. NHS Information Centre. Health Survey for England 2008: Physical Activity and Fitness, 2009. http://www.ic.nhs.uk/statistics-and-data-collections/ health-and-lifestyles-related-surveys/health-surveyfor-england/health-survey-for-england--2008physical-activity-and-fitness. 